\title{
ENRAIZAMENTO, CIRCUITOS CURTOS E COMBATE À POBREZA RURAL NO SEMIÁRIDO NORDESTINO: UMA EXPERIÊNCIA DE DESENVOLVIMENTO RURAL NO QUILOMBO TABACARIA
}

\author{
João Rafael Gomes de Morais ${ }^{1}$ \\ Luíz Fernando Barbosa Gomes Magalhães²
}

\begin{abstract}
RESUMO
O objetivo do artigo é analisar o processo de desenvolvimento local do Quilombo Tabacaria sob a ótica da constituição de circuitos curtos agroalimentares através do enraizamento de negócios rurais. Parte-se da ideia de que essa abordagem pode contribuir tanto no combate à pobreza rural, quanto na valorização do patrimônio socioambiental do semiárido nordestino. Para tanto, utilizaram-se métodos de pesquisa-ação com a finalidade de elaborar e executar um plano de ação participativo. Entre os resultados da pesquisa, é possível afirmar que a constituição de negócios em comunidades rurais empobrecidas é diretamente dependente da tecitura de relações sociais recíprocas e solidárias entre seus membros, sendo, muitas vezes, condição sine qua non para a criação e a oferta de produtos e serviços diferenciados.
\end{abstract}

Palavras Chaves: circuitos curtos, desenvolvimento local, enraizamento.

\section{EMBEDDEDNESS, SHORT CIRCUITS AND COMBATING RURAL POVERTY IN THE NORTHEASTERN SEMIARID REGION: A RURAL DEVELOPMENT EXPERIENCE IN QUILOMBO TABACARIA}

\begin{abstract}
The objective of the article is to analyze the local development process of Quilombo Tabacaria from the perspective of the constitution of short agro-food circuits through the rooting of rural businesses. It starts with the idea that this approach can contribute both to fighting rural poverty and to enhancing the socio-environmental heritage of the Northeastern semi-arid region. For that, action research methods were used in order to develop and execute a participatory action plan. Among the results of the research, it is possible to affirm that the constitution of businesses in impoverished rural communities is directly dependent on the creation of reciprocal and solidary social relations among its members, being, many times, a sine qua non condition for the creation and supply of products. and differentiated services.
\end{abstract}

Keyword: embeddedness, local development, short circuits.

\footnotetext{
1 Graduado em Ciências Sociais (UFRPE). Mestrado em Sociologia (UFPE). Doutorando em Ciências Sociais (UFCG). E-mail: joao.rafael@yahoo.com.br

2 Graduado em Psicologia (UFAL). Mestrado em Sociologia (UFAL). Doutorando em Sociologia (UFPE). Email: nandobgm@gmail.com
} 


\section{INTRODUÇÃO}

Neste trabalho, pretendemos analisar a dinâmica de desenvolvimento local/rural em curso na Comunidade Quilombola Povoado Tabacaria (Quilombo Tabacaria) $^{3}$ sob a ótica da construção de circuitos curtos agroalimentares e de serviços turísticos, através do enraizamento de negócios rurais alicerçados em potenciais identitários, socioculturais, ambientais e territoriais do quilombo.

O Quilombo Tabacaria é uma das comunidades rurais mais precárias do estado de Alagoas (ALAGOAS, 2015), sendo composta oficialmente por 89 famílias em situação de extrema pobreza. Por esse motivo, o estudo calcou sua metodologia com base nos preceitos da pesquisa-ação, recorrendo a diferentes instrumentos (reuniões, visitas técnicas, entrevistas, oficinas temáticas) de coleta dos dados para construção do plano de ação. Para Thiollent (1985), a pesquisa-ação é realizada em estreita associação com uma ação, ou com a resolução de problema coletivo no qual os pesquisadores e os participantes estão envolvidos. A participação dos pesquisadores neste contexto se deu por intermédio do Instituto Nordestino de Cidadania e Moraria Popular (HABITAR) ${ }^{4}$, que, desde 2014 até a presente data, vem desenvolvendo um plano de ação conjunto com as famílias pertencentes ao Quilombo Tabacaria com a finalidade de promover o desenvolvimento local. A investigação desenvolvida conformou-se também em um processo de prestação de assistência técnica e extensão rural.

A apresentação dos resultados da pesquisa seguiu as etapas propostas por Mckay e Marshall (2001). Desse modo, a exposição está estruturada em seis seções. A primeira é composta por essa introdução. Na segunda, realizamos um breve resgate histórico da trajetória do Quilombo Tabacaria e dos seus problemas centrais. Na terceira, buscamos analisar as possiblidades de desenvolvimento local da comunidade quilombola a partir de um olhar teórico embasado no enraizamento socioeconômico e na construção de circuitos curtos. Na quarta parte detalhamos o processo de compartilhamento de responsabilidades, execução, monitoramento, avaliação e ajustes do plano de ação. Na quinta seção, apresentamos os principais resultados alcançados e identificamos os principais desafios a serem enfrentados. $\mathrm{Na}$ parte final do estudo apresentamos as conclusões sobre o processo de pesquisa.

\section{QUILOMBO TABACARIA: TRAJETÓRIA E PRINCIPAIS DESAFIOS}

O Quilombo Tabacaria é um dos exemplos mais cristalinos do contexto de desigualdade social e do descaso das políticas públicas para com os estratos mais empobrecidos da população brasileira. Segundo Costa (2015), a comunidade quilombola Tabacaria está inserida geograficamente na região onde, no século XVII e XVIII, orbitaram os "Mocambos dos Palmares", organização social na qual a "Serra da Barriga" (em União dos Palmares/AL) possuía centralidade política e estratégica ${ }^{5}$. Desse modo, Costa (2015) discorre sobre a possiblidade de que as famílias quilombolas de Tabacaria possam ser descendentes desses mocambos palmarinos, vinculando a comunidade a uma história de resistência e luta de mais de 300 anos.

A perseguição estatal sobre os quilombos repercutiu negativamente em todo o século XIX (e parte do XX), contribuindo de forma contundente para a marginalização da comunidade. Após a abolição da escravatura, essas populações

\footnotetext{
${ }^{3}$ Localizado no município de Palmeira dos Índios, em Alagoas.

${ }^{4}$ Os pesquisadores compõem, respectivamente, o quadro diretivo e o quadro técnico da instituição.

${ }^{5}$ A distância entre os municípios de União dos Palmares e Palmeira dos Índios é de 72 km.
} 
foram sofrendo novas pressões advindas da expansão pecuária extensiva desenvolvida pelos fazendeiros da região. Essa expansão das áreas de pastagem ensejou um conjunto de conflitos (violentos e não-violentos) entre a comunidade e os fazendeiros, o que paulatinamente desempossou essas famílias de seus territórios tradicionais de residência e produção agrícola.

No início do século XXI, no entanto, o panorama de marginalização da comunidade passou a ser mitigado pela ação de uma série de atores. Um grupo de missionários relacionados à Igreja Católica passou a dar assistência à comunidade, ainda que de maneira transitória. Essa rede de suporte era composta também por pessoas vinculadas a setores da esquerda cristã alagoana, por intelectuais ligados ao movimento negro e por pesquisadores da Universidade Federal de Alagoas (UFAL). Em 2004, esse conjunto de agentes, por sua vez, trouxe à comunidade a representante regional da Fundação Cultural Palmares (FCP). A instituição ofereceu suporte técnico ao processo de reconhecimento do território quilombola, o que provocou a criação da Associação dos Remanescentes de Quilombo Tabacaria, como etapa obrigatória do procedimento de reconhecimento da comunidade.

Em 2005, Tabacaria foi oficialmente certificado, fato que gerou o aumento das ameaças e dos atos violentos dos fazendeiros contra as famílias da comunidade que passaram a acampar na Fazenda Boa Vista - território historicamente ocupado por seus ancestrais quilombolas. No decorrer dos anos de 2007 e 2008, houve a tramitação dos procedimentos de reconhecimento e demarcação do território, culminando com o decreto de desapropriação do território de 410 hectares $^{6}$, em 2009, pelo então Presidente Luiz Inácio da Silva. As resistências, os desafios e as condições de vida da comunidade, nesse período, foram abordadas em alguns estudos acadêmicos (CHASIN, 2009; MARQUES; MENDES; SILVA, 2012; VIEIRA, et al, 2013; LUSA, 2014), uns de maneira mais tangencial, outros de forma mais aprofundada.

Em 2014, das 89 famílias quilombolas, cerca de 31 residiam em casas de lona, e as demais residiam em casas de taipa e alvenaria precária (ALAGOAS, 2015). Em 2007, cerca de $70 \%$ dos quilombolas dependiam da renda gerada pelo Programa Bolsa Família para sobreviver. As rendas externas obtidas fora de suas unidades de produção (prestação de serviços) não geravam rendimentos suficientes para reprodução das famílias. O quilombo possui um amplo repertório de saberes tradicionais oriundos de sua história e trajetória. Entre eles, estão conhecimentos relacionados à fiação do algodão, à produção artesanal, à manipulação de ervas medicinais e a manifestações culturais (o reisado e a banda de pífano). Esses fatores socioculturais fazem com que as famílias quilombolas não tenham uma relação estritamente mercantil com a terra, mas, na verdade, compreendam-na como um território de vida e de memória (COSTA, 2015).

De maneira geral, em 2014, a carência de infraestrutura e de serviços na localidade era evidente. Ela estava expressa na dimensão energética (a maioria das residências possuía ligação irregular de energia), hídrica (existia apenas um poço artesiano desativado, pequenos barreiros, dois açudes e abastecimentos esporádicos por meio de carros pipas), sanitária (a maioria das pessoas fazia suas necessidades fisiológicas na vegetação local), produtiva (famílias descapitalizadas e sem tecnologias apropriadas para iniciar empreendimentos agrícolas e pecuários), creditícia (famílias não tinham acesso a linhas de crédito) e documental (a maioria não possuía declaração de aptidão ao Pronaf - DAP). Esse conjunto de elementos

\footnotetext{
${ }^{6}$ O módulo fiscal no município de Palmeira dos Índios é de 35 hectares. Dividindo os 410 hectares do quilombo pelas 89 famílias, chegamos ao resultado de 4,60 hectares em média por família.
} 
propiciou as condições ideais para a reprodução da pobreza e da exclusão social das pessoas e da comunidade nos contextos local e regional.

Figura 1 - Condições de moradia em Tabacaria em 2014

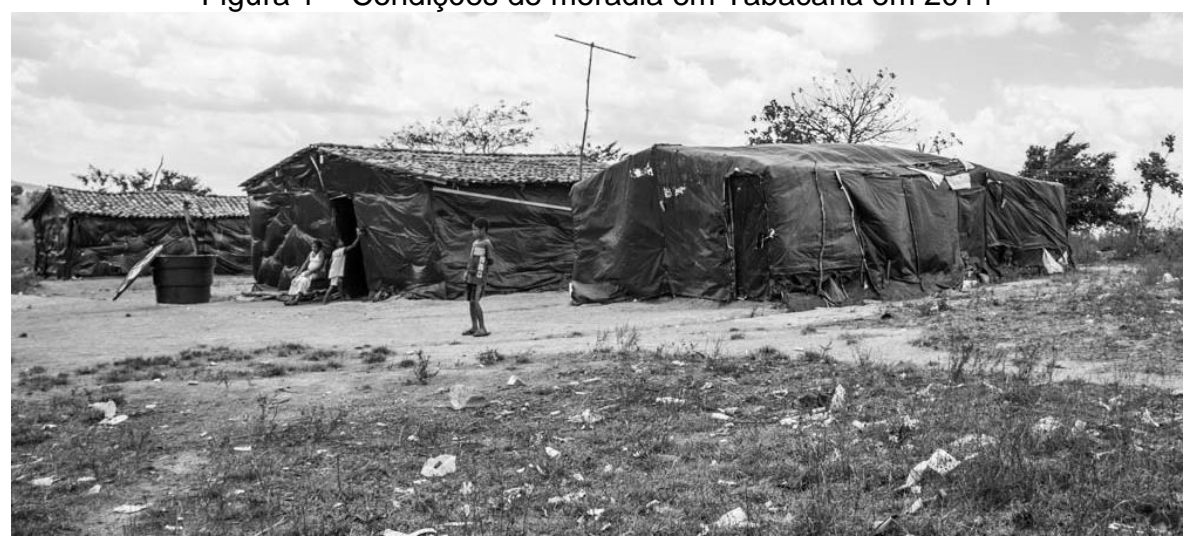

Fonte: Fotografia dos autores

Ao longo do processo de desapropriação dos terrenos e do reconhecimento do território quilombola, os atores externos anteriormente citados, paulatinamente, deixaram de exercer o papel de suporte à articulação comunitária ${ }^{7}$, fato que repercutiu diretamente na perda de capacidade de mobilização dos/as associados/as do Quilombo Tabacaria. O universo de parcerias da comunidade ficou limitado, então, à FCP e ao Instituto de Colonização e Reforma Agrária (INCRA). Nesse momento, tanto o governo municipal quanto o governo estadual não se mostraram sensibilizados com as demandas latentes da comunidade por habitação, alimentação, produção, saúde, transporte e renda.

No início do segundo semestre de 2014, por intermédio da FCP e do Instituto Habitar, tivemos o primeiro contato com as lideranças da Associação do Quilombo. Através da realização de uma série de reuniões, visitas técnicas e oficinas temáticas com o conjunto das 89 famílias, foram definidas as necessidades mais urgentes para a comunidade: 1) a construção de unidades habitacionais; e 2) a implantação de projeto de geração de trabalho e renda. Naturalmente existiam outras demandas, mas, por ordem de prioridade, o conjunto das famílias definiu esses dois pontos como os objetivos centrais.

\footnotetext{
${ }^{7}$ Entre outros fatores, esse processo de distanciamento pode ser explicado tanto pela mudança de governo estadual ocorrida após 2006 - fato que desarticulou uma série de redes ligadas à pauta quilombola no Estado - , quanto pelas dificuldades destes atores em lidar com as peculiaridades organizacionais da comunidade.
} 
Figura 2 - Reunião do Instituto Habitar na comunidade em 2014

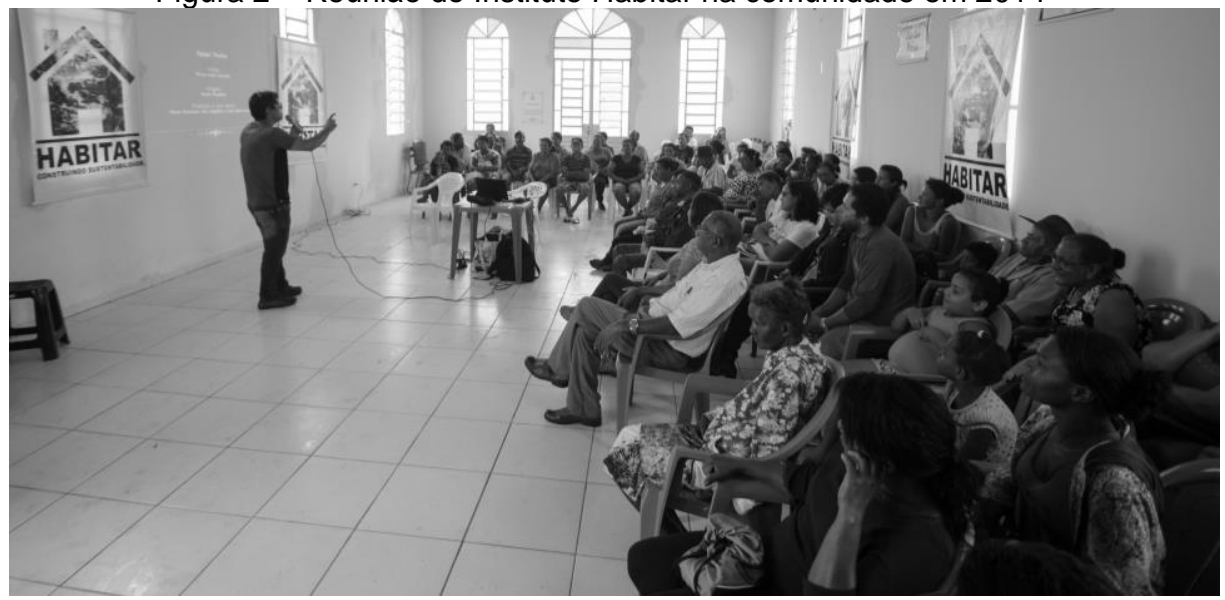

Fonte: Fotografia dos autores

\section{EMPREENDIMENTOS RURAIS ENRAIZADOS: UMA ESTRATÉGIA DE COMBATE À POBREZA RURAL NO SEMIÁRIDO NORDESTINO}

No Brasil, uma parcela significativa dos estabelecimentos rurais familiares, comunidades indígenas e quilombolas está circunscrita na região semiárida nordestina. Das regiões com regime climático similar no planeta, ela é a mais populosa (MARENGO, 2008). Um conjunto de fatores, sejam eles fundiários, sociais, econômicos, ambientais, tecnológicos e políticos, concorre para que essas populações possuam baixos indicadores de educação, produtividade e renda. Essa confluência propicia a reprodução de quase metade da pobreza rural existente em nosso país.

De certa maneira, essas populações rurais são bloqueadas de suas potencialidades em graus e maneiras distintas pelas forças políticas e econômicas dominantes na agricultura e no meio rural brasileiro (WANDERLEY, 2017). Esse bloqueio é potencializado principalmente por dois fatores. O primeiro é o fator ambiental: a região é caracterizada pela existência de solos rasos e alcalinos, alta insolação, deficiência hídrica e secas periódicas. O segundo fator é o socioeconômico: a maior parte da população rural habita e produz em minifúndios (ou através de relações precárias de acesso à terra), possuindo baixo grau de escolaridade, capitalização (investimento e custeio), sem acesso a recursos hídricos, utilizando tecnologias inapropriadas e inserida em mercados locais pouco dinâmicos (SILVA; COSTA, 2014).

Esses elementos contribuem para conformação de um quadro de insegurança sistêmica (alimentar, hídrica, laboral e financeira) proveniente tanto de fatores sofridos "da porteira para dentro" como por fatores sofridos "da porteira para fora". Ambos os aspectos podem ser potencializados ou minimizados conforme o contexto institucional e o mercado local. Eles influenciam e delimitam as estratégias de geração de receitas (agrícolas e não-agrícolas), bem como as condições de produção e comercialização de produtos e serviços (BUAINAIN; GARCIA, 2013).

Isto posto, não é exagero afirmar que a região semiárida nordestina pode ser considerada como um dos principais desafios não solucionados da política 
agrícola, ambiental e social do Brasil. É imprescindível inserir as populações rurais empobrecidas na dinâmica econômica e social moderna, assegurando concomitantemente a preservação dos recursos naturais como um patrimônio de toda a sociedade (WANDERLEY, 2000).

$\mathrm{Na}$ atualidade, inúmeras pesquisas relacionadas ao meio rural brasileiro apontam que a dinamização das economias de base familiar perpassa pela adoção de uma abordagem calcada no processo de "construção de mercados" (MALUF, 2004). Essa abordagem privilegia a constituição de circuitos curtos de produção, distribuição e consumo de alimentos e serviços diferenciados em âmbito comunitário, local e regional, como parte integrante da concepção de formação de sistemas alimentares descentralizados (SAD), conformando-se em uma estratégia de segurança alimentar e nutricional (MALUF; LUZ, 2017). Essa perspectiva objetiva aproximar os produtores e os consumidores locais e regionais, diminuir custos, melhorar a qualidade dos produtos e serviços ofertados, valorizar o saber local e aproveitar as vantagens comparativas ambientais e territoriais.

$\mathrm{O}$ enfoque dos circuitos curtos sugere que os empreendimentos de base familiar no meio rural brasileiro sejam fomentados e organizados a partir de dinâmicas enraizadas em relações (e aptidões) socioculturais que valorizem sua localidade, tradição, origem, natureza e o seu modo de produção, sendo esses seus maiores apelos comerciais (NIEDERLE, 2009).

O conceito de enraizamento (embeddedness), concebido inicialmente por Polanyi ${ }^{8}$, está relacionado ao processo de formação de significado para as ações dos atores inseridos num contexto ou ambiente institucional historicamente determinado. Ele influencia as estruturas sociais, enraizadas em discussões e práticas sociais que se transformam em regras, normas, costumes e hábitos, influenciando assim o comportamento dos indivíduos. Nos casos específicos, em que alguns tecidos societários não possuem equipamentos socioeconômicos enraizados, o "livre" mercado torna-se o imperativo categórico, influenciando as relações sociais ao ponto de fomentar o surgimento de condutas individualistas e padrões morais que não privilegiam a coletividade (SCHNEIDER; ESCHER, 2011).

Quando o sociólogo Mark Granovetter reinterpretou o conceito de enraizamento de Karl Polanyi, contribuiu para a sociologia econômica em três níveis. O primeiro se refere à compreensão do conceito de enraizamento como sendo relacionado às redes sociais, demonstrando que a ação econômica é permeada por relações sociais. A segunda contribuição refere-se à construção de tipologias que permitem correlacionar distintos padrões de comportamento econômico. Finalmente, sua reinterpretação introduziu a noção de "força dos laços fracos", que possibilita analisar a relação entre redes e o papel estratégico da posição dos atores nesses respectivos tecidos sociais. Nessa perspectiva, o conceito de enraizamento possibilitaria compreender a ação econômica como sendo permeada por redes e relações sociais nas quais os atores estão inseridos e podem transitar, considerando suas posições e interesses (WILKINSON, 2002).

No Brasil, essa chave analítica tem contribuído de forma significativa para a compreensão dos fenômenos que envolvem a agricultura familiar e o

\footnotetext{
${ }^{8} \mathrm{O}$ conceito de enraizamento foi elaborado por Karl Polanyi ao analisar as repercussões socioeconômicas do declínio das quatro instituições (sistema de equilíbrio de poder, padrão internacional do ouro, o mercado autorregulável e o estado liberal) que alicerçavam a sociedade do século XIX. Para o autor, a ruína das quatro instituições possibilitou a constituição de economias desterritorializadas, desvinculadas das redes societárias onde estão circunscritas, ou seja, não estão socialmente e politicamente enraizadas nas localidades onde os sistemas produtivos funcionam de fato (POLANYI, 2000).
} 
desenvolvimento rural. Essa perspectiva lançou novas luzes sobre os circuitos curtos e os mercados agroalimentares alternativos (WILKINSON, 1999; NIEDERLE, 2009; DAROLT, 2013; TRICHES; SCHNEIDER, 2015); os processos agroindustriais familiares e as dinâmicas de agregação de valor de produtos artesanais (WILKINSON, 2002; MALUF, 2004); a geração de serviços diferenciados e o desenvolvimento local/territorial de municípios de médio e pequeno porte no interior do país (SCARABELOT; SCHNEIDER, 2012; TEDESCO, 2013; MORAES, 2016); e nas ações de combate à inflação e promoção da soberania e segurança alimentar e nutricional (MALUF; LUZ, 2017; MALUF, 2017).

Refletindo especificamente sobre nosso objeto de estudo, questionamos: é possível, através da constituição de empreendimentos de economia solidária enraizados em potenciais identitários, socioculturais, ambientais e territoriais, dinamizarmos as economias das comunidades rurais com alto índice de pobreza, déficit hídrico e baixos níveis educacionais e organizativos?

A noção de enraizamento (formulada por Polanyi e reinterpretada por Grannovetter) possibilita compreender o desenvolvimento socioeconômico como algo que não dependente apenas da implantação e aperfeiçoamento dos processos produtivos e financeiros nas comunidades rurais, mas aponta, na verdade, para a importância da qualificação das relações e dos laços sociais entre os integrantes de uma comunidade, e da própria comunidade com seu entorno. Essa abordagem considera que a economia e os mercados não são produtos apenas das trocas materiais e financeiras, mas instituições permeadas por relações e práticas sociais:

\begin{abstract}
A discussão sobre embeddedness é associada a relações de confiança e reciprocidade entre atores locais. Mercados enraizados seriam então aqueles em que as relações de trocas são fortemente mediadas por convenções sociais formadas pelas interações que ocorrem no "contexto social mais imediato", nas redes sociais que se estabelecem na localidade, na região ou no território. (NIEDERLE, 2009, p. 18).
\end{abstract}

Observando a realidade brasileira, Maluf (2004) avalia que a agricultura familiar diversificada de pequena escala possui potencial para estabelecer vínculos produtivos e comerciais em âmbito local e regional voltados para a produção, distribuição e consumo de produtos e serviços diferenciados, a partir de iniciativas que valorizem a relação direta entre produtor/a e consumidor/a. O pesquisador salienta que esse processo de "construção de mercados" demanda uma reconversão produtiva que deve ser feita gradualmente. Nesse sentido, pontua que "os projetos devem ter como ponto de partida os recursos existentes e considerar as alternativas colocadas pelos agricultores, inclusive a dinâmica dos processos que já estejam em curso" (MALUF, 2004, p. 312).

Quando aplicado ao Quilombo Tabacaria, esse conjunto de elementos lança luzes sobre duas questões relevantes para o desenvolvimento local da comunidade. A primeira refere-se à importância da tecitura de relações solidárias e recíprocas entre os integrantes do quilombo e com o seu entorno. Essa dinâmica social pode extrapolar os limites do território através do estabelecimento de novas parcerias e relações comerciais. A ampliação dessa rede deve-se dar através do processo de valorização e qualificação de seus produtos (culturais, paisagísticos, alimentares e serviços). A segunda refere-se à importância do efetivo enraizamento (físico e socioeconômico) das famílias em seu território ancestral. Sem habitações dignas, sem iniciativas de geração de trabalho e renda, com sua cultura ancestral pouco valorizada, os quilombolas de Tabacaria não conseguem visualizar um 
horizonte de permanência e desenvolvimento, o que muitos ao êxodo, na busca de melhores oportunidades de vida.

Para que possamos vislumbrar qualquer processo de fomento de negócios que possam gerar trabalho em renda na comunidade, devemos primeiro considerar, portanto, alguns elementos identificados no processo participativo de formulação do Plano de Ação, relacionados a: educação, economia, infraestrutura produtiva, capacidade associativa e organizativa, além de aspectos identitários.

A educação é um dos elementos mais desafiadores dentro desse contexto. O baixo nível educacional contribui diretamente para a reprodução do estado de miséria e extrema pobreza, dificultando o acesso e a implementação de conhecimentos e tecnologias que ampliem as iniciativas que garantam a segurança alimentar e a geração de trabalho e renda. Torna-se fundamental que os empreendimentos fomentados tragam consigo os princípios da reciprocidade, solidariedade e corresponsabilidade.

O baixo dinamismo econômico na comunidade contribuiu para marginalização dos seus membros, resultando numa organização comunitária desprovida de habilidades ligadas à autonomia, cooperação e autogestão. Mesmo o quilombo tendo uma experiência exitosa de conquista da terra, esse elo social não se estendeu para outras frentes de luta, como por exemplo na busca de soluções e estratégias coletivas de geração de trabalho e renda (motivado pela ausência de recursos e bens em comum que contribuíssem na organização de empreendimentos de caráter associativo). $\mathrm{Na}$ ausência desses insumos, as famílias quilombolas ficaram presas a uma posição de subserviência, dependência, sem oportunidades de formação e progressão técnica, ficando refém, historicamente, de relações clientelistas e exploratórias. Esse contexto provocou o surgimento de um modelo de desenvolvimento ineficaz e técnicas produtivas inadequadas ao bioma, muitas vezes incongruentes com as vocações climáticas e territoriais.

Em decorrência do baixo nível educacional e da frágil economia local, o quilombo não possui infraestrutura produtiva, ou seja, não possui instrumentos, equipamentos e parcerias que contribuam para a dinamização da economia comunitária. A produção agrícola está restrita às culturas de "subsistência" (feijão e milho), poucas são as famílias que possuem produção pecuária, em muito inviabilizada pelo difícil acesso aos recursos hídricos. As atividades produtivas desenvolvidas na comunidade não garantem a segurança alimentar das famílias, transformando o quilombo, em tempos de estiagem, num local sem produção, sem renda, sem oportunidades.

A situação de exclusão socioeconômica não propiciou a formação de um ambiente associativo entre as pessoas. A escassez de recursos contribuiu para o surgimento de condutas individualistas, buscando soluções de curto prazo voltadas para $o$ atendimento das necessidades imediatas dos seus respectivos núcleos familiares. A perda desses laços de solidariedade tradicionais está diretamente ligada ao enfraquecimento das fronteiras étnicas (POUTIGNAT; STREIFF-FENART, 1997) que sustentavam a identidade coletiva comunitária no quilombo, processo que por sua vez é produto das centenas de anos de marginalização, estereotipia e invisibilidade diante das políticas estatais. Por compreender a importância fundamental do fortalecimento do protagonismo local, optamos pelo método da pesquisa-ação no intuito de criar espaços de participação, discussão, formulação e execução de ações, possibilitando assim a identificação de novas alternativas e soluções com vistas à melhoria das condições de vida.

Desse modo, diversas barreiras são interpostas ao desenvolvimento e manutenção dos recursos que poderiam ser operacionalizados para geração de trabalho e renda, em um contexto permeado por dificuldades em reconhecer ou 
eleger marcadores étnicos que possam sustentar uma identidade cultural que conecte coerentemente o conjunto de bens simbólicos reconhecidamente presentes na comunidade. O patrimônio cultural, ambiental, paisagístico e histórico do quilombo, sintetizados em sua gastronomia e em suas manifestações artísticas e culturais (música, dança, histórias), por exemplo, podem compor o conjunto dos atrativos impulsionadores do processo de dinamização da economia local.

De fato, identificamos que o quilombo Tabacaria possui potenciais turísticos e ambientais inexplorados, que ainda não dialogam com o conjunto das estratégias laborais das famílias. No alto da serra em que residem, o clima é muito agradável ao anoitecer, principalmente nos períodos de inverno, possuindo grande beleza paisagística. Do ponto de vista sociocultural, o quilombo possui um expressivo patrimônio histórico (resguardando mais de 300 anos de história oral) diretamente vinculado ao Quilombo dos Palmares, além de diversas manifestações culturais (reisado, banda de pífano, gastronomia).

O território possui uma expressiva área de vegetação nativa e áreas de reserva legal, possuindo uma trilha que leva aos pontos históricos onde os refugiados do Quilombo do Palmares residiram. Esses locais foram identificados no laudo antropológico e embasaram o processo de reconhecimento da comunidade como remanescente de quilombo. Esses potenciais podem ser utilizados como instrumentos de incentivo produtivo e diversificação de renda através da divulgação dos pontos turísticos e históricos da comunidade. Dessa forma, fica evidente então que o maior desafio é criar

Uma diversidade de inovações sociotécnicas e institucionais; ou seja, de práticas locais de trabalho e produção e de arranjos sociopolíticos territorialmente institucionalizados, adaptados pelos agricultores às suas possibilidades de produção socioeconômica (SCHNEIDER; ESCHER, 2011, p. 210).

\section{O PLANO DE AÇÃO E AS RESPONSABILIDADES COMPARTILHADAS: A DINÂMICA DE IMPLANTAÇÃO, MONITORAMENTO, AVALIAÇÃO}

O Plano de Ação foi composto por duas demandas prioritárias elencadas pelos integrantes da comunidade. A primeira era a construção de 89 unidades habitacionais. A segunda demanda estava relacionada ao desenvolvimento de atividades produtivas que gerassem trabalho e renda. O compartilhamento de responsabilidades entre o Instituto HABITAR e os dirigentes da Associação do Quilombo Tabacaria foi estabelecido nos seguintes termos: a HABITAR ficaria responsável pela parte técnica, ou seja, pela elaboração dos projetos de habitação e de empreendedorismo rural; a associação da comunidade ficaria responsável pelo processo de diálogo e mobilização de apoios políticos (prefeitura, vereadores, deputados, governo estadual e governo federal).

Considerando a limitação dos recursos de ambas as partes, foi acordado que os esforços iniciais seriam feitos na busca de recursos e políticas públicas para resolução da questão habitacional da comunidade. Entre as opções disponíveis, identificamos o Programa Nacional de Habitação Rural (PNHR) vinculado ao Programa Minha Casa Minha Vida (PMCMV) como a opção mais viável para atendimento da demanda comunitária. Iniciou-se, então, o processo de elaboração do projeto técnico habitacional, o que culminou na discussão e aprovação coletiva de uma planta residencial $\left(50 \mathrm{~m}^{2}\right)$. 
Figura 3 - Primeira casa construída pelo projeto em 2016

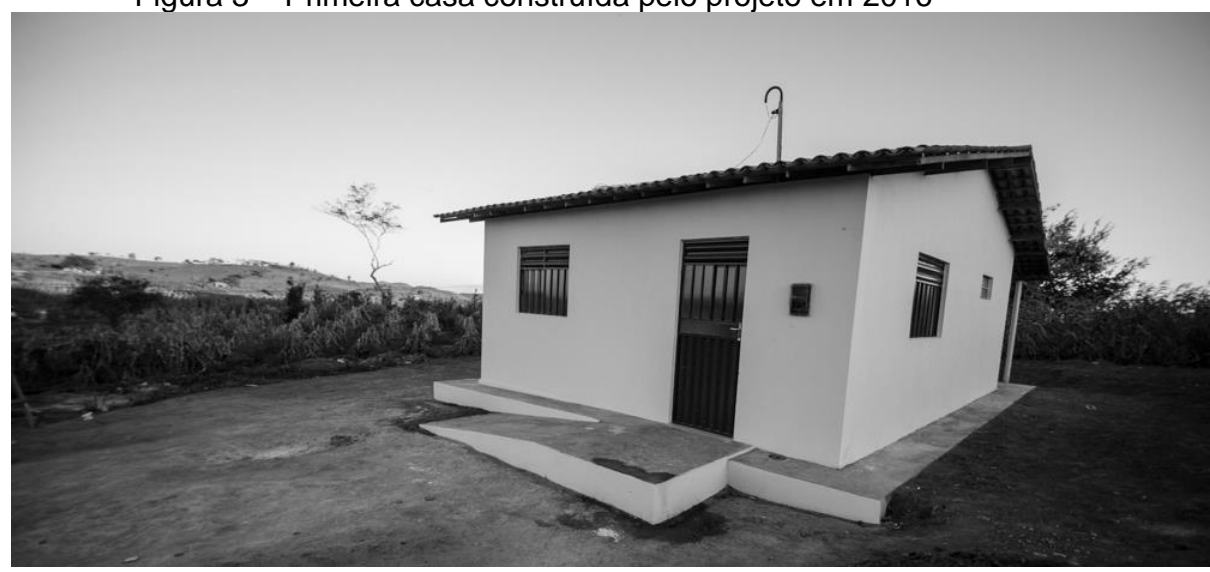

Fonte: Fotografia dos autores

$\mathrm{Na}$ fase de organização documental do projeto habitacional para o PNHR, as famílias enfrentaram grandes dificuldades para cumprimento das exigências, principalmente aquelas relacionadas à comprovação do estado civil. Por essa circunstância, o projeto foi organizado com apenas 50 unidades habitacionais. Nessa etapa, foram priorizadas as famílias que se encontravam em pior condição de moradia - aquelas que estavam residindo em lonas, casas de taipa e de alvenaria precária. A proposta foi protocolada na Caixa Econômica Federal (CEF) no dia 15/10/2014. Até aquele momento, apenas a representação regional da FCP estava apoiando as demandas da comunidade, tendo papel importante de articulação junto ao Ministério das Cidades e à CEF, órgãos responsáveis pelo PNHR.

O projeto habitacional apresentado foi aprovado em março de 2015. Mas, por uma série de fatores políticos e financeiros decorrentes daquele período do Brasil, a proposta habitacional só foi contratada no dia 10 de maio de $2016^{9}$. Esse intervalo de tramitação do projeto foi marcado por um longo processo de articulação e diálogo com agentes institucionais externos por parte do Instituto HABITAR, no entanto, para as famílias quilombolas, esse momento se configurou como um período de desmobilização e expectativa. Essa conjuntura agravou-se diante da impossibilidade de apresentação de novos projetos habitacionais no âmbito do PNHR, o que impediu que as 39 famílias restantes tivessem acesso ao programa. Esse processo de reorganização interna da comunidade só foi retomado, de fato, com a contratação oficial das 50 unidades habitacionais (início das obras). A mobilização da comunidade em torno do projeto habitacional foi evidentemente reforçada pela adoção do regime de autoconstrução, que possibilitou o engajamento de parentes com experiência em obras, gerando trabalho e renda no quilombo.

Diante do avanço — ainda que parcial — da ação prioritária anteriormente definida, iniciou-se, então, o processo de diagnóstico participativo sobre a situação produtiva do quilombo. Dessa forma, realizamos um novo ciclo de debates e visitas técnicas, buscando levantar elementos que pudessem potencializar as oportunidades de geração de trabalho e renda, numa perspectiva que levasse em consideração a valorização dos aspectos identitários e ambientais locais.

\footnotetext{
${ }^{9} \mathrm{O}$ vídeo intitulado Habitação Rural PNHR: uma experiência de moradia digna no Quilombo Tabacaria está disponível no Youtube (https://www.youtube.com/watch?v=hdySzOvYWKY).
} 
Após o ciclo de escuta e debate realizado junto à comunidade, definiram-se três eixos estratégicos de atuação do projeto de geração de trabalho e renda. O primeiro eixo estava relacionado à criação de mecanismos de segurança alimentar dos membros da comunidade. O segundo eixo buscaria fomentar iniciativas produtivas de cunho agroecológico e orgânico, justamente por considerar que esses modelos produtivos são mais adaptados às condições climáticas e econômicas da comunidade. O terceiro eixo estava relacionado à integração da cultura local, reconhecendo-a como insumo estratégico para geração de trabalho e renda no quilombo. Essa dinâmica poderia ser construída através da valorização das manifestações culturais (reisado, banda de pífano, história do quilombo) e da gastronomia local, ou até mesmo através da utilização sustentável dos potenciais turísticos étnico-culturais e paisagísticos existentes na comunidade.

No dia 05 de junho de 2017, o Fundo Socioambiental da Caixa Econômica Federal (CEF) publicou o edital de seleção de projetos intitulado "Desenvolvimento e Cidadania 01/2017". No chamamento, foi disponibilizando o valor máximo de R\$ $200.000,00$ (duzentos mil reais) para investimento em 20 (vinte) projetos sociais. Em diálogo com a direção da associação do quilombo, definimos que o projeto social iria focar no trabalho socioprodutivo com as mulheres quilombolas.

Norteados pelos três eixos citados anteriormente, elaborou-se a proposta de intervenção ${ }^{10}$. O objetivo do projeto era valorizar o patrimônio social, cultural e ambiental do Quilombo Tabacaria através da estruturação de negócios rurais. Para tanto, foi prevista a implantação de 04 unidades de Produção Agroecológica Integrada e Sustentável (PAIS) ${ }^{11}$, consorciando horticultura e avicultura, sendo geridas de forma associativa, rotativa e alternada pelo grupo de mulheres. Além das hortas, foi prevista a constituição de 01 cozinha comunitária através da elaboração de um cardápio local e da aquisição de equipamentos e utensílios para estruturação do negócio. Congregado a esses esforços, o projeto previa também o fomento ao turismo étnico-cultural. Essa dinâmica se daria através do levantamento dos potenciais turísticos, seguido pela construção de roteiros, culminando na realização de 03 exposições fotográficas e na produção de 01 audiovisual, incentivando e fortalecendo a identidade cultural quilombola. Esses empreendimentos coletivos seriam retroalimentados e ampliados por meio da implantação e gestão de um Fundo Rotativo. Os negócios rurais seriam instituídos através de um Regimento Interno (RI), contendo as regras e procedimentos de gestão das hortas, da cozinha e do fundo rotativo. Esperava-se que a prática da gestão coletiva de bens, contribuísse para criação de protagonismo e condutas reciprocas e solidárias entre as responsáveis pelos negócios.

Os empreendimentos previstos no projeto foram planejados para funcionarem de forma independente, mas com funções complementares, cumprindo o seguinte fluxo: a) 04 unidades PAIS geridas de forma partilhada entre as mulheres. Cada horta composta por 5 integrantes. O resultado produtivo das hortas possui 0 objetivo, primeiro, de garantir a segurança alimentar das famílias envolvidas e, secundariamente, gerar renda para as mulheres e retroalimentar o Fundo Rotativo; b) $O$ fortalecimento da gastronomia se conecta às estratégias produtivas, possibilitando a comercialização dos produtos in natura e processados (através de

10 Título do projeto: "Mulheres Quilombolas e Identidades Culturais: Implantação e Gestão de Empreendimentos e Sistemas Financeiros Solidários como Estratégia de Promoção da Agroecologia, Segurança Alimentar e Nutricional, Geração de Trabalho e Renda".

11 O PAIS é uma tecnologia social originalmente elaborada pelo engenheiro agrônomo senegalês Aly Ndiaye, amplamente difundida no Brasil pelo SEBRAE e pela Fundação Banco do Brasil. A metodologia propõe a integração produtiva e ecologicamente sustentável de uma horta, pomar e avicultura. 
receitas tradicionais do saber acumulado pelas mulheres); c) A atração do fluxo turístico do quilombo seria então incentivado através da divulgação do produto audiovisual e das exposições fotográficas, destacando os atrativos socioculturais e ambientais do quilombo. A complementariedade entre os negócios multiplicaria as possibilidades de geração de trabalho e renda.

Figura 4 - Fluxograma do projeto em 2017

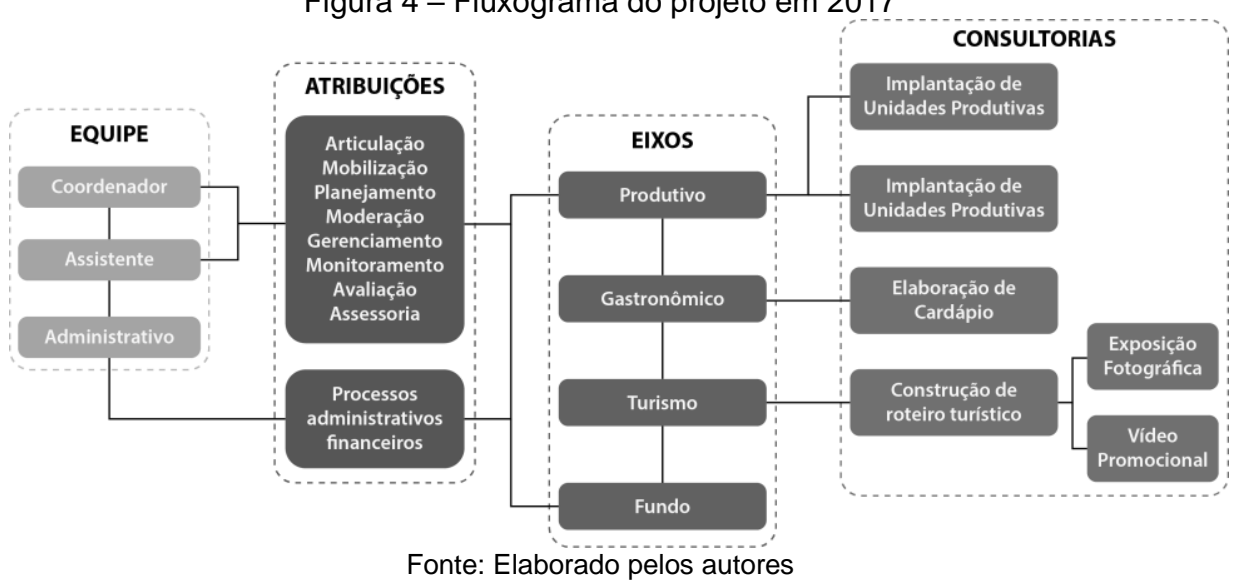

Em outras palavras, o projeto foi uma tentativa de construção de um circuito curto de produção, beneficiamento de comercialização de alimentos saudáveis como suporte a estratégia de prestação de serviços turísticos e culturais pela comunidade, utilizando os recursos ambientais e territoriais disponíveis.

No dia 10/08/2017, foi divulgado no Diário Oficial da União o resultado final da seleção. A proposta apresentada foi selecionada em quarto lugar. O Acordo de Cooperação Financeira (ACF) foi assinado no dia 24/11/2017. Em janeiro de 2018, iniciamos as ações do projeto com a capacitação de 30 mulheres (72 horas). Desse conjunto, 20 mulheres foram selecionadas para compor as 4 unidades PAIS e 10 passaram a fazer parte da cozinha comunitária.

$\mathrm{O}$ desembolso financeiro da $1^{\circ}$ parcela estava relacionado à implantação das quatro unidades PAIS. Para etapa de preparação do solo e sua respectiva adubação, promoveu-se mutirão, contando com a participação das mulheres beneficiárias, seus familiares e a equipe técnica do projeto. As hortas foram munidas, cada uma, com caixas d'água de 5.000 mil litros e sistemas de irrigação por gotejamento, criando as condições mínimas de armazenamento e distribuição de água, no intuito de otimizar o recurso natural escasso.

As hortas PAIS foram dotadas de capital de giro inicial. Deste modo, foram adquiridos equipamentos, aves, sementes e insumos para realização do primeiro ciclo produtivo. A comercialização dos produtos excedentes das hortas ocorreu na própria comunidade. Essa produção foi comprada por moradores da redondeza e por visitantes. Algumas hortas conseguiram vender sua produção ao Programa de Aquisição de Alimentos (PAA). 
Figura 5 - Unidade PAIS “Dandara” em 2018

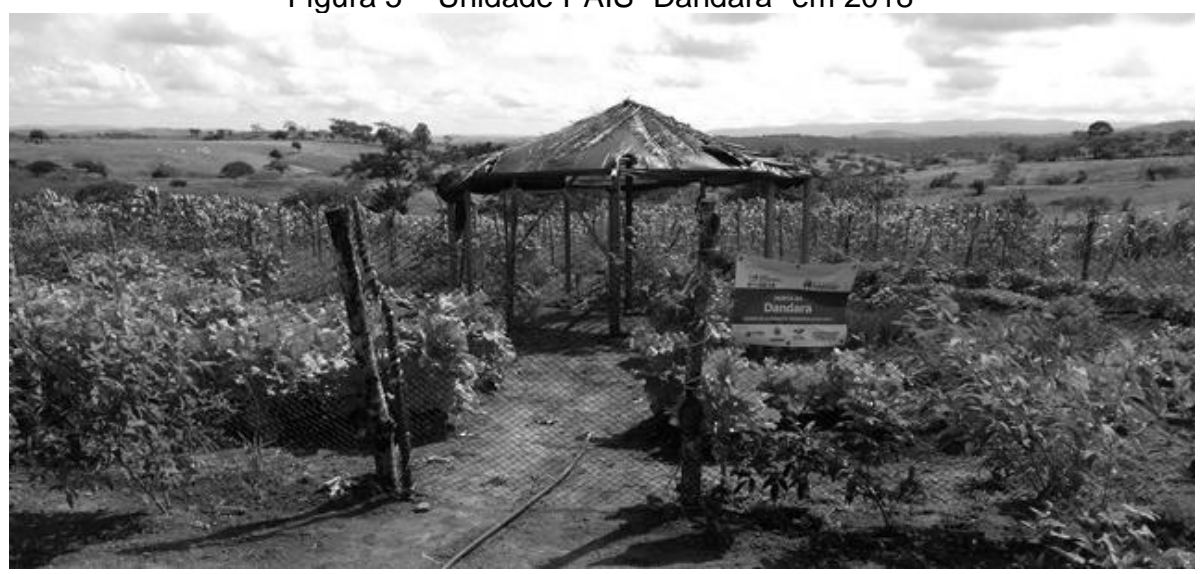

Fonte: Fotografia dos autores

Os desafios para a construção de relações recíprocas, solidárias e de corresponsabilidade entre as mulheres surgiram logo no processo de organização do mutirão, e se estendeu até o processo de implantação e gestão das hortas. Mesmo que os grupos tenham sido formados por escolhas mútuas e por afinidades de parentesco, muitos conflitos emergiram ${ }^{12}$, em sua maioria, provenientes de dois fatores: a) a gestão e o controle sobre a divisão de trabalho; b) a contabilidade, prestação de contas e divisão dos lucros entre o grupo. É importante evidenciar que todas as envolvidas elaboraram e formularam os termos de funcionamento contidos no Rl. Além da construção conjunta das normas, foi eleita uma componente de cada grupo para exercer o papel de coordenação dos trabalhos. Parte das mulheres teve grandes dificuldades em seguir as regras de gestão e repartição dos lucros e, principalmente, de criar relações de confiança mútua ${ }^{13}$. Deste modo, das 4 hortas implantadas, 3 apresentaram acentuados problemas de gestão, condição que demandou acompanhamento constante da equipe técnica do projeto, através de reuniões para mediação dos conflitos e assessoria na gestão financeira e produtiva.

$\mathrm{Na}$ animação de ações de desenvolvimento rural em comunidades empobrecidas, deve-se sempre levar em consideração a pouca experiência dessas pessoas no manejo compartilhado de recursos materiais e financeiros. Do ponto de vista pedagógico, os conflitos de interesse conformam-se, na verdade, nos principais insumos de equalização dos projetos individuais com os projetos coletivos. A individualidade emerge no coletivo como fato, cristalizado numa atitude ou numa conduta. O surgimento do conflito possibilita o debate e o ajuste de trajetória. Niederle (2009), estudando os mercados convencionais e os alternativos, recorre a Granovetter para explicar os desafios inerentes aos ajustes de conduta necessários para a transformação dos mercados em espaços mais recíprocos e solidários

\footnotetext{
12 Os conflitos não ficaram restritos entre as mulheres integrantes do empreendimento produtivo. Parte dos maridos e companheiros das participantes do projeto, como um todo, boicotou a iniciativa. Alguns deles consideravam que o projeto deveria ter priorizado os homens da comunidade, em detrimento da participação e do protagonismo das mulheres.

${ }^{13}$ A dádiva (MAUSS, 1974), por exemplo, tem sido uma chave analítica importante no entendimento das relações de reciprocidade em comunidades rurais no Brasil. Sobre o assunto, indicamos a leitura dos livros Camponeses do Brasil entre a troca mercantil e a reciprocidade e Sociedades e Organizações Camponesas do professor Eric Sabourin (2009; 2011).
} 
organizados em rede. Acreditamos que essa reflexão também pode nos ajudar a explicar que:

A má-fé ou o egoísmo não deixam de existir em prol do desinteresse, da confiança e do altruísmo de relações idealmente fundadas em laços de solidariedade recíproca. As redes permitem todo tipo de comportamento, inclusive o oportunismo e a desonestidade, o que faz com que nenhuma ação seja previsível ex-ante. Os atores podem usar sua centralidade na rede para influenciar o comportamento dos demais em benefício próprio (NIEDERLE, 2009, p. 19).

O oportunismo e o individualismo não são características intrínsecas das populações rurais empobrecidas, elas também emergem nas mais diversas classes sociais. Deduz-se que essas manifestações são expressões miméticas da cultura econômica dominante na contemporaneidade, em que os benefícios imediatos, muitas vezes, suplantam os acordos que trarão resultados benéficos a médio e longo prazo.

O enraizamento de empreendimentos rurais em comunidades empobrecidas no semiárido nordestino demanda a disponibilidade de recursos materiais, financeiros e simbólicos. Uma experimentação efetiva só ocorre quando os sujeitos têm acesso aos meios para executar seus objetivos e metas. Nessa trajetória, ocorre o desenvolvimento de capacidades e competências. Na medida em que vão estabelecendo relações recíprocas e solidárias, vão construindo e reforçando os mecanismos de escuta mútua e de repactuação dos acordos.

Contudo, esse contexto de conflitos e dificuldades de gestão não se repetiu no processo de implantação da cozinha comunitária do quilombo. No segundo estágio de execução do projeto, em agosto de 2018, além de realizarmos a aquisição dos equipamentos e utensílios para estruturação do espaço culinário, o projeto ofertou uma oficina de capacitação com as 10 mulheres responsáveis pela iniciativa gastronômica. Na ocasião, contou-se com a assessoria de uma profissional de nutrição para elaboração participativa do cardápio da cozinha comunitária, e para orientação sobre as normas sanitárias e de boas práticas culinárias.

Figura 6 - Cozinha comunitária do Quilombo em 2018

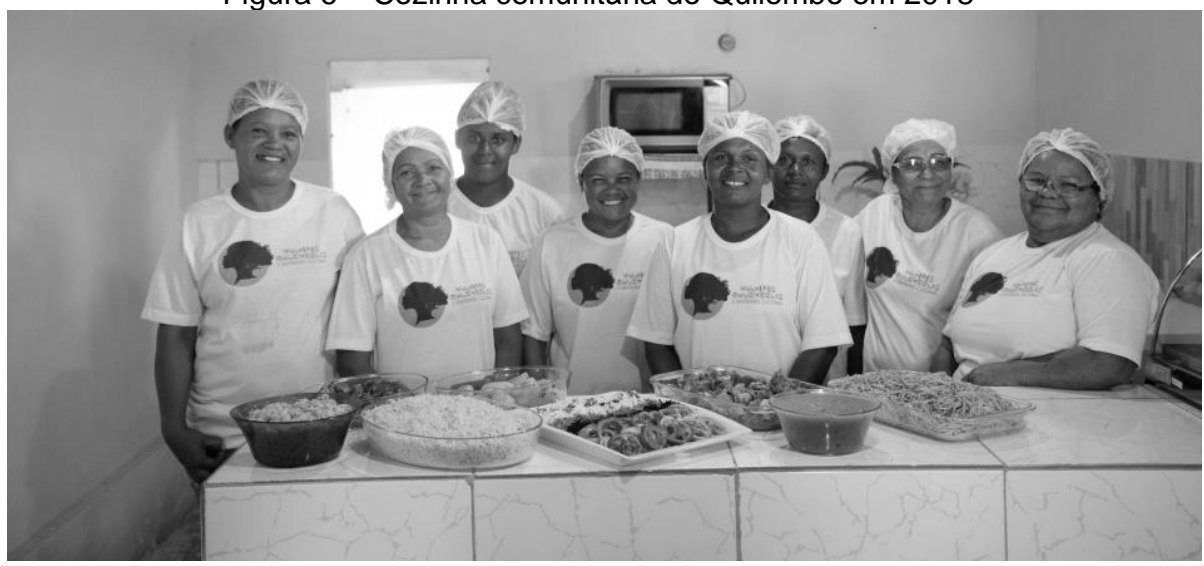

Fonte: Fotografia dos autores 
As mulheres responsáveis pela cozinha conseguiram implantar a metodologia de gestão social de maneira satisfatória, fazendo com que o empreendimento fortalecesse os laços de reciprocidade e solidariedade, integrandoo ao processo de geração de trabalho e renda. A cozinha tem como objetivo beneficiar parte dos alimentos produzidos pelas hortas e dar suporte ao fluxo turístico do quilombo. Para além dessas possibilidades, o grupo também poderá comercializar seus produtos junto aos programas institucionais de aquisição de alimentos e em festas tradicionais das comunidades vizinhas.

No mês de outubro de 2018, realizamos a implantação do Fundo Rotativo das mulheres quilombolas. Fora disponibilizado o valor de $R \$ 20.000,00$ (vinte mil reais) para financiamento de negócios rurais que colaborem com a valorização cultural e ambiental do quilombo. As integrantes do projeto, juntamente com os dirigentes da associação quilombola, definiram, em Regimento Interno, as linhas de investimento e as taxas de juros que seriam cobradas mensalmente (no mínimo de $2 \%$ e no máximo de $3 \%$ ) pelo Fundo. Participaram dessa primeira rodada de crédito apenas o grupo de mulheres vinculadas à cozinha comunitária (pois o projeto não disponibilizou recursos financeiros para o capital de giro inicial). As mulheres responsáveis pelas hortas, por fatores relacionados à prestação de contas dos respectivos empreendimentos, não apresentavam as condições mínimas para participação na primeira rodada de crédito. De modo geral, é importante destacar que a gestão coletiva sobre o fundo rotativo gerou inúmeros conflitos entre as participantes do projeto.

Por fim, apresentou-se à comunidade o vídeo em que são divulgados os potenciais turísticos do quilombo ${ }^{14}$ e as imagens que compuseram a exposição fotográfica itinerante, realizada em três campi da Universidade Estadual de Alagoas (UNEAL).

\section{PRINCIPAIS RESULTADOS E DESAFIOS VINDOUROS}

De modo geral, promover ações de desenvolvimento local/rural alicerçadas na constituição de negócios rurais enraizados, em comunidades empobrecidas no semiárido nordestino, não é uma tarefa trivial e nem possui roteiro pré-estabelecido. Por isso mesmo, é importante compreender a extensão rural como um processo de comunicação, educação e transformação mútua (FREIRE, 1983), cuja finalidade é ofertar melhores condições de vida às populações rurais, em seus mais variados aspectos.

No âmbito da habitação rural, no dia 18 de outubro de 2017, foram concluídas e entregues as 50 moradias com cisternas. As 39 famílias restantes continuaram sem acesso ao PNHR após duas tentativas frustradas (2017 e 2018). Em relação à gestão das hortas PAIS, algumas mulheres continuaram a ter dificuldades no compartilhamento de responsabilidades. Em janeiro de 2019, realizaram-se reuniões com as mulheres e representantes da associação da comunidade. Foi identificado que o principal problema de gestão estava relacionado à ausência de prestação de contas por parte de 3 grupos. Como alternativa de solução do problema, foi sugerida a criação de um Comitê Gestor (CG) para auxiliar na gestão financeira das hortas. $O C G$ foi composto pelo quadro diretivo da associação da comunidade, que formulou as novas regras de gestão das hortas, com orientação do Instituto HABITAR.

14 O vídeo intitulado Turismo Étnico-Cultural no Quilombo Tabacaria está disponível no Youtube (https://www.youtube.com/watch?v=Xnmp7CfQfzw\&t=52s ) 
Nem todas as participantes aceitaram as novas regras de gestão; logo, solicitaram afastamento das hortas. Cerca de $50 \%$ das mulheres fundadoras do projeto permanecem por vontade própria, concordando com o novo modelo de gestão adotado. A substituição dessas componentes foi outra responsabilidade atribuída à CG. É importante ressaltar que a iniciativa foi exitosa do ponto de vista econômico, mostrou-se promissora e com significativa capacidade de geração de renda (mesmo com a dificuldade de acesso à água nos períodos de verão). Conforme a estratégia de venda (na comunidade, porta a porta ou feira livre da cidade) adotada, o incremento na renda mensal de cada componente das hortas chegou a oscilar entre $R \$ 80,00$ e $R \$ 200,00$ reais. Além de significar acesso a alimentos frescos, a horta possibilitou um pequeno incremento de renda, ocupando apenas parcialmente as mulheres.

A cozinha comunitária vem realizando o beneficiamento e a comercialização de produtos alimentícios com relativo sucesso. Grupos de universitários, pesquisadores, estudantes do ensino médio e turistas têm realizado visitas à comunidade. O prato principal do cardápio é a "Tilápia ao molho de Amendoim". A cozinha comercializa seus produtos através de pratos feitos e de autosserviço, cobrando um valor entre $R \$ 15,00$ e $R \$ 20,00$, respectivamente, por pessoa. Conforme o agendamento de visitas, a cozinha planeja a aquisição de alguns produtos das hortas PAIS. Essa integração tem ocorrido, porém, ela é limitada à demanda eventual de visitantes. O principal desafio do empreendimento culinário é acessar políticas de aquisição de alimentos públicas e construir parcerias com a iniciativa privada para formalização de contratos de fornecimento de refeições. O fluxo turístico por si só é insuficiente para garantir o pleno funcionamento da cozinha, no entanto, sem ela, não há como organizar visitações ao quilombo.

Quanto à constituição do sistema financeiro local através do fundo rotativo, observa-se a seguinte circunstância: a partir das decisões supracitadas, o CG também assumiu a gestão sobre os recursos do fundo. O comitê definiu que o valor do financiamento seria de $R \$ 500,00$ reais. Conforme cada tomadora fosse quitando e renovando crédito, esse teto poderia ser reajustado. Após o período de superação dos problemas de gestão das hortas, as mulheres também passaram a tomar financiamentos, e as componentes da cozinha foram renovando os seus. Nesse tocante, os conflitos não surgiram das beneficiárias tomadoras de crédito; eles emergiram de um dos membros da administração do CG. Problemas de contabilidade e comprovação de depósitos instabilizaram, em parte, o funcionamento do fundo. Após reunião com as integrantes do fundo rotativo e do $\mathrm{CG}$, foram tomadas as medidas reparatórias de conduta e controle financeiro.

Esses resultados não são definitivos. Compreendemos a mudança social enquanto um processo educacional que cria e desloca conflitos; e nesse trajeto, cria e identifica novas oportunidades que gradativamente podem proporcionar (ou não) melhoria nas condições de vida das pessoas envolvidas. Por esse motivo, consideramos exitoso o processo de implantação dos negócios rurais articulados em circuitos curtos. Esses empreendimentos geraram um ambiente de segurança alimentar para as famílias, além de trabalho e renda. No entanto, o processo de enraizamento de pessoas e de novos modelos organizacionais a partir de preceitos recíprocos e solidários é um projeto de longo prazo.

Esse esforço demanda um amplo processo de aprendizado individual e coletivo. Um dos elementos que contribuem para permanência do cenário de empobrecimento (além da ausência de capital e de condições ambientais e tecnológicas) é a ausência de confiança e parceria entre as famílias e os componentes de uma comunidade. A mudança de uma postura reativa e 
assistencialista para uma postura proativa e empreendedora requer tempo, instrumentos didáticos e pedagógicos que fomentem essa tomada de consciência e alteração de conduta.

\section{CONCLUSÕES}

Neste trabalho, buscamos retratar a dinâmica de desenvolvimento local/rural no quilombo Tabacaria, a partir da constituição de circuitos curtos agroalimentares e de serviços turísticos, através do enraizamento de negócios rurais. A experiência em questão aponta para as contribuições instrumentais do referencial teórico-metodológico, permitindo-nos lançar luzes sobre a importância do patrimônio sociocultural, ambiental e territorial dentro das estratégias de extensão rural voltadas à segurança alimentar e à dinamização socioeconômica e ao combate à pobreza rural.

A execução, mesmo que parcial, do Plano de Ação, possibilitou o reposicionamento da imagem pública do quilombo Tabacaria no município de Palmeira dos Índios e no Estado de Alagoas. Quase sempre retratado na mídia como um lugar de miséria (CHAGAS; NUNES, 2016), o quilombo passou a ser visto como local de manifestações culturais genuínas e com forte atrativo turístico. Um exemplo desse reposicionamento de imagem ocorreu em 2019, quando a comunidade foi tema da campanha "Amo Palmeira \#SOUDAQUI" promovida pela prefeitura (PALMEIRA DOS ÍNDIOS, 2019). Tal mudança deve-se à valorização identitária e territorial do quilombo, conjugada à modesta melhoria de qualidade de vida propiciada pelos negócios rurais implementados. Decerto, o escopo do presente artigo não possibilitou uma exposição detalhada de todas as repercussões da ação, questões que, por sua vez, serão exploradas em análises futuras.

Diante dessas reflexões, conclui-se que o desenvolvimento local/rural não depende apenas da "injeção" de recursos financeiros ou da introdução de novas atividades produtivas (agrícola e não agrícola) em comunidades rurais empobrecidas. A noção de enraizamento destaca o papel da organização social dentro do processo do desenvolvimento. A constituição de relações sociais recíprocas e solidárias entre os integrantes de uma comunidade empobrecida é, muitas vezes, condição sine qua non para que ocorram a criação e a oferta de produtos e serviços diferenciados.

\section{AGRADECIMENTOS}

O presente trabalho foi realizado com apoio da Coordenação de Aperfeiçoamento de Pessoal de Nível Superior - Brasil (CAPES) - Código de Financiamento 001. Agradecemos a leitura e as sugestões de aperfeiçoamento realizadas pela equipe editorial da Revista Extensão Rural.

\section{REFERÊNCIAS}

ALAGOAS. Secretária de Estado do Planejamento, Gestão e Patrimônio. Estudo sobre as comunidades Quilombolas de Alagoas. Maceió: SEPLAG, 2015. 46 p. Disponível em: http://www.iteral.al.gov.br/gpaf/assessoria-tecnica-dos-nucleosquilombolas-e-indigenas-astnqi/comunidades-quilombolas-dealagoas/documentos/estudocomunidadesquilombolas.pdf. Acesso em: 20 dez. 2015.

BUAINAIN, A. M.; GARCIA, J. R. Contextos locais ou regionais: importância para a viabilidade econômica dos pequenos produtores. In: NAVARRO, Z. S.; CAMPOS, S. 
K. A. A pequena produção rural e as tendências do desenvolvimento agrário brasileiro: ganhar tempo é possível? Brasília, CGEE, p. 133-176, 2013.

CHAGAS, M.; NUNES, P. Quilombolas vivem em situação de miséria em Alagoas. Portal G1 Alagoas, 20. nov. 2016. Disponível em: http://g1.globo.com/al/alagoas/noticia/2016/11/quilombolas-vivem-em-situacao-demiseria-em-comunidades-de-alagoas.html. Acesso em: 20 jan. 2020.

CHASIN, A. C.M. 20 Anos de Regularização Fundiária de Territórios Quilombolas: um balanço da implementação do direito à terra estabelecido pela Constituição Federal de 1988. Revista Política Hoje, v. 18, n. 2, p. 158-183, 2009.

COSTA, A. C. E. Quilombo de Povoado Tabacaria. Coleção Terras de Quilombo: Maceió; Belo Horizonte, NUQ/FAFICH, OJB/FAFICH, NEAD, 2015. 20p.

DAROLT, M. Circuitos curtos de comercialização de alimentos ecológicos: reconectando produtores e consumidores. In: NIEDERLE, P. A.; ALMEIDA, L.; VEZZANI, F. M. Agroecologia. Práticas, mercados e políticas para uma nova agricultura. Curitiba: Kairós, p. 139-170, 2013.

FREIRE, P. Extensão ou Comunicação? 8. ed. Rio de Janeiro; Paz e Terra, 1983. $93 \mathrm{p}$.

LUSA, M. G. Políticas públicas no semiárido alagoano e a resistência quilombola e camponesa frente à exploração capitalista. Revista de Políticas Públicas, São Luís, Número Especial, p. 447-452, jul. 2014.

MALUF, R. S; LUZ, L. F. Sistemas alimentares descentralizados: um enfoque de abastecimento na perspectiva da soberania e segurança alimentar e nutricional. In: MALUF, R. S; FLEXOR, G. (orgs). Questões Agrárias, Agrícolas e Rurais: conjunturas e políticas públicas. Rio de janeiro: e-papers, p. 214-224, 2017.

MALUF, R. S. Abastecimento alimentar, inflação de alimentos e o contexto urbano no Brasil. In: MALUF, R. S; FLEXOR, G. (orgs). Questões Agrárias, Agrícolas e Rurais: conjunturas e políticas públicas. 1 ed. Rio de janeiro: e-papers, p. 179-193, 2017.

MALUF, R. S. Mercados agroalimentares e a agricultura familiar no Brasil: agregação de valor, cadeias integradas e circuitos regionais. Ensaios FEE, Porto Alegre, v. 25, n 1, p. 299-322, 2004.

MARENGO, J. A. Água e mudanças climáticas. Estudos Avançados, v. 22, n. 63, p. 83-96, 2008.

MARQUES, A. C. N.; MENDES, C. B.; SILVA, W. C. M. Pelo direito de ser diferente: a situação atual das comunidades quilombolas em Alagoas, Brasil. Educte: Revista Cientifica da IFAL, v.3, n. 2, p.1-13, jul./dez. 2012.

MAUSS, M. Ensaio sobre a dádiva. forma e razão da troca nas sociedades arcaicas. In: Sociologia e Antropologia. São Paulo: Edusp, 1974. 
McKAY, J.; MARSHALL, P. The Dual Imperatives of Action Research. Information Technology \& People, v. 14, n. 1, p. 46-59, 2001.

MORAES, J. L. A. Agricultura familiar, sistemas agroalimentares localizados - sials e as dinâmicas de desenvolvimento dos territórios rurais. Redes, Santa Cruz do Sul, v.21, n.3, p. 238-256, set./dez. 2016.

NIEDERLE, P. A. Delimitando as fronteiras entre mercados convencionais e alternativos para a agricultura familiar. Extensão Rural, Santa Maria, v.16, n 18, p. 5-37, jul./dez. 2009. Disponível em: https://periodicos.ufsm.br/extensaorural/article/view/5593. Acesso em: 20 jan. 2020.

PALMEIRA DOS ÍNDIOS. Reisado do quilombo Tabacaria é tema da Campanha Amo Palmeira \#SOUDAQUI. Portal de Notícias da Prefeitura, 4. abr. 2019. Disponível em: https://palmeiradosindios.al.gov.br/reisado-do-quilombo-da-tabacariae-tema-da-campanha/. Acesso em: 20 jan. 2020.

POLANYI, K. A grande transformação: as origens da nossa época. 2. ed., Rio de Janeiro: Elsevier, 2000.

POUTIGNAT, P. STREIFF-FERNART. Teorias da etnicidade. São Paulo: Unesp, 1997. $256 \mathrm{p}$.

SABOURIN, E. Camponeses do Brasil: entre a troca mercantil e a reciprocidade. Rio de Janeiro: Editora Garamond, 2009. 332p.

SABOURIN, E. Sociedades e organizações camponesas: uma leitura através da reciprocidade. Porto Alegre; Editora da UFRGS, 2011. 272p.

SCARABELOT, M.; SCHNEIDER, S. As cadeias agroalimentares curtas e desenvolvimento local: Um estudo de caso no município de Nova Veneza/SC. Revista faz Ciência Unioeste, v. 15, n 20, p. 101-130, jan./jun. 2012.

SCHNEIDER, S.; ESCHER, F. A contribuição de Karl Polanyi para a sociologia do desenvolvimento rural. Sociologias, Porto Alegre, v. 13, n. 27, p. 180-219, mai./ago. 2011.

SILVA, A. G. da; COSTA, F. B. Os estabelecimentos rurais de menor porte econômico do Semiárido nordestino frente às novas tendências da agropecuária brasileira. In: BUAINAIN, A. M.; ALVES, E.; SILVEIRA, J. M. de; NAVARRO, Z. (ed. técnicos). 0 mundo rural do século 21: a formação de um novo padrão agrário e agrícola. Brasília: Embrapa, p. 947-977, 2014.

TEDESCO, J. C. Economia de circuitos curtos, da qualidade e dos territórios étnicos: uma análise da dinâmica produtiva e mercantil na rota das salamarias - Norte e Nordeste do RS. Extensão Rural, Santa Maria, v. 20, n 3, set./dez. 2013. Disponível em: https://periodicos.ufsm.br/extensaorural/article/view/8116. Acesso em: 20 jan. 2020.

THIOLLENT, M. Metodologia de pesquisa-ação. São Paulo; Cortez, 1985. 
TRICHES, R. M.; SCHNEIDER, S. Alimentação, sistema agroalimentar e consumidores: novas conexões para o desenvolvimento rural. Cuadernos de Desarrollo Rural, v. 12, n. 75, p. 55-75, 2015.

VIEIRA; J. L. G.; MAGALhAES, F. A.; COSTA, L. V. C.; LIMA, S. M. V. C. Quilombolas em Alagoas: as raízes africanas e o direito à demarcação dos territórios. Refletindo o Direito: Revista CESMAC, n. 1, p.1-18, 2013.

WANDERLEY, M. N. B. "Franja periférica", "pobres do campo", Camponeses": dilemas da inclusão social dos pequenos agricultores familiares. In: DELGADO, G. C.; BERGAMASCO, S. M. P. P. (Orgs). Agricultura familiar brasileira: desafios e perspectivas de futuro. Brasília: Ministério do Desenvolvimento Agrário, p. 66-83, 2017.

WANDERLEY, M. N. B. A emergência de uma nova ruralidade nas sociedades modernas avançadas: o rural como espaço singular e ator coletivo. Estudos sociedade e agricultura, Rio de Janeiro, v. 8, n. 15, p. 87-145, 2000.

WILKINSON, J. Perfis Emergentes do setor agroalimentar. In: MALUF, R. S.; WILKINSON, J. (org). Reestruturação do sistema agroalimentar: questões metodológicas e de pesquisa. Redecapa, p. 27-44, 1999.

WILKINSON, J. Sociologia econômica, a teoria das convenções e o funcionamento dos mercados: "inputs" para analisar os micro e pequenos empreendimentos agroindustriais no Brasil. Ensaios FEE, Porto Alegre, v. 23, n. 2, p. 805-824, 2002. 